\title{
(Im)migrant trajectories
}

\author{
Lourdes Torres $^{1}$
}

Accepted: 25 January 2022 / Published online: 8 February 2022

(๑) The Author(s), under exclusive licence to Springer Nature Limited 2022

Mainstream media tends to portray immigrants either as masses of undifferentiated others scurrying across our borders or as destitute, hapless victims. Ample research demonstrates that such dehumanizing portrayals have the noxious effect of negatively shaping public perceptions and policy (see, for example, the work of Leo Chavez and Otto Santa Ana). So, it is refreshing to turn to our journal for narratives that capture the abounding complexities, intricate layers, and multiple dimensions of migrant life. We share stories of undocumented student activists engaging in "risktaking movidas" as well as farmworkers' challenges in securing decent housing. We also share articles that capture the diverse paths immigrants who have secured basic rights take as they pursue personal and political integration in the United States. These articles detail how immigrants engage in acts of self-making and communitymaking in terms of personal and political representation and economic security. This rich collection of articles powerfully counters the media's dangerous misrepresentation of our people.

We open with Ramirez Solórzano's provocative analysis of undocumented/ undocuqueer youth activism. He demonstrates how four Miami Dade College students (three of whom were undocumented) took dangerous risks in their fight for migrant rights. Bravely walking 1,500 miles from Miami, Florida, to Washington, DC, these young people sought to bring attention to the plight of immigrants, protest government inactivity concerning immigration rights, and advocate for a path to citizenship for undocumented people. Ramirez Solórzano describes how their 2015 Trail of Dreams action entailed numerous risks for these four students as they traveled in a small group across southern states with a long history and culture of hostility toward immigrants and other people of color. Along the way they engaged in coalition-building with African Americans and other progressive peoples who met with and engaged in solidarity actions with the marchers. The article offers an inspiring example of multiracial movement-building for the mutual liberation of people of color.

In a different but no less contentious setting, Kennedy Saldanha's project shines a light on the lives and struggles of migrant farmers. As the food movement in the US

Lourdes Torres

ltorres@depaul.edu

1 DePaul University, Chicago, IL, USA 
attests, the human beings who labor to get food on our tables often languish in invisibility. Saldanha visited migrant housing camps across Michigan, traveling with staff from service organizations and conversing with migrants. He documents the substandard living conditions farmworkers are forced to endure. He views this as form of structural violence that perpetuates persistent and enduring harm. Saldanha provides valuable insight into the lives of farmworkers when they are not laboring and highlights the work of outreach workers who engage with farmworkers to advocate for their rights. He makes the point that not only are the horrid housing camps invisible to most people, but so too are the full lives and contributions of farmworkers in the Midwest and beyond. He calls for more outreach to farmworkers and attention to this appalling reality.

The next three articles look at less precarious life experiences of immigrants who have established a sense of belonging and political and economic power. Nathan Rossi presents the seldom-discussed narrative of transnational adoption in the Latino community. During the Salvadoran war, thousands of children were taken from their families by militias. These children were either raised by soldiers and their contacts or put up for adoption internationally. Nathan Rossi shares a case study of one young Salvadoran adoptee, Nelson de Witt, and the way he and his family document their experiences in digital culture. Rossi argues that this space provides them the freedom to explore a complex transnational experience outside of specific geographical locations. He argues that the digital context allows de Witt to engage in a journey of "unforgetting" and "self-making" quite removed from the romanticized stereotypes of international adoption rescue stories.

Turning to a political context, Yalidy Matos and Domingo Morel explore the question of how Latinx immigrant groups acquire political representation via electoral politics. Matos and Morel focus on Dominicans-an understudied community in Latino studies - to consider various routes to political incorporation as measured by the number of Dominican elected officials in three settings that have growing Dominican communities: Washington Heights/Inwood, New York City; Providence, Rhode Island; and Miami/Miami-Dade, Florida. The authors consider the various factors that influence Dominican political incorporation, including population size, institutional context, and vitality of civic and political organizations. Interestingly, they demonstrate that there is no single winning strategy. Sometimes political incorporation is facilitated by participating in pan-ethnic identification, whereas other times incorporation is advanced by emphasizing a Dominican identity.

Michael J. Pisani contributes to conversations about incorporation at an economic sphere, as he considers how Latinos establish themselves and shape their lives in the US as entrepreneurs. As is generally recognized, Latinos are a driving force of business growth in the US and help maintain a robust economic and entrepreneurial ecosystem nationally as they provide for their families. Pisani does a deep dive into what these businesses look like, utilizing a large database of more than four thousand Latino-owned businesses to examine their market orientation, including the types of products they sell and who they see as their customer base (ethnic and non-ethnic communities). One stereotype that the article interrupts is the idea that Latino businesses are primarily oriented toward marketing Latino products to Latino customers. 
In addition to these contributions that engage evolving (im)migrant narratives, we are pleased to include in this issue a reflexiones pedagógicas essay highlighting \#BrownInChicago, a Chicago-based, collective Latinx youth project. Led by a collaboration of activists and scholars (Juliet de Jesús Alejandré, Jesse Mumm, Violet Gallardo) this innovative effort centered both community organizing and popular education. The authors make a call for working with youth to ensure that they understand themselves as both subjects and directors of their historical research as they investigate their own cultural origins.

Enjoy!

Publisher's Note Springer Nature remains neutral with regard to jurisdictional claims in published maps and institutional affiliations. 